\title{
Caractérisation, transformation et valorisation de déchets d'éviscération de volaille de Kénitra, Maroc
}

\author{
Laarousi Elmoualdi*, Hicham Labioui, Mohammed El Yachioui, \\ et Mohammed Ouhssine
}

Laboratoire de biotechnologie microbienne, Département de biologie, UFR Amélioration et transformation microbienne et végétale, Faculté des sciences, Université Ibn Tofaïl, I4000 Kénitra, BP 133, Maroc.

(Reçu le 13 Septembre 2005, accepté le 07 Janvier 2006)

*Correspondance, courriel : elmoualdi@yahoo.fr

\section{Résumé}

La production du poulet de chair à l'échelle industrielle a connu un développement considérable au cours des vingt-cinq dernières années et génère une grande quantité de déchets. Un procédé biologique permettant la transformation de ces déchets en un produit stable à été mis au point en se basant sur l'utilisation de bactéries lactiques et de levures acidifiantes possédant un fort pouvoir fermentatif.

Dix souches de bactéries lactiques et onze de levures ont été isolées. La bactérie lactique LBLI et la souche de levure LSSI ont été retenues pour constituer le levain de fermentation. Leur association permet une réduction du temps de fermentation ef l'obtention d'un produit fertilisant de qualité hygiénique satisfaisante. La stabilisation a été obtenue après dix jours de fermentation. Le pH atteint alors 3,9 avec une acidité de $1,4 \%$, l'azote total est de 2,2 \%, le potassium de $56,5 \%$, le phosphate de $10 \%$. Les coliformes sont absents et les staphylocoques et streptocoques sont à un niveau non inquiétant $(<10 \mathrm{ufc} / \mathrm{g})$.

Mots-clés : Déchets de volaille, levures, bactéries lactiques, fermentation, acidité.

\section{Abstract \\ Characterization, transformation and valorization of poultry evisceration waste of Kénitra, Morocco}

The production of chickens at industrial level has known a considerable development since the 25 last years and produces a great quantity of waste. A biological process allowing the transformation of this waste in a stable product was undergone, using lactic 
bacteria and yeasts with great acidifying capacity and high fermentative potential.

Ten lactic bacterium and eleven yeast were isolated. The lactic bacterium LBLI and the yeast LSSI were retained to constitute the leaven of fermentation. Their association allowed a reduction of the fermentation time, and gave a product of fertilizing quality and satisfactory final hygienic quality. After ten days fermentation, the stabilisation was observed. pH reached 3.9 with $1.4 \%$ acidity of total nitrogen $2.2 \%$, potassium $56.5 \%$, phosphate $10 \%$. Coliformes were eliminated while staphylococci and streptococci were at a non-worrying level $(<10 u f c / g)$.

Keywords : Scrap poultries, yeast, lactic bacteria, fermentation, acidity.

\section{1. introduction}

Le développement des activités industrielles (agroalimentaire, papeterie, industries chimiques, industries de transformation, ...) entraîne des déchets résiduels qui ont un impact négatif sur le milieu récepteur [1-17]. Ces déchets, qui sont des substances minérales et organiques, sont dans la plupart des cas déversés dans la décharge publique.

L'aviculture marocaine a connu au cours des vingt-cinq dernières années un essor considérable. La production de viande de volaille est passée de 29000 tonnes en 1970 à 230000 tonnes en 1997, enregistrant un taux de progression moyen annuel de $8 \%$; parallèlement, la consommation annuelle de viande de volaille par habitant a évolué de 2,3 kg en 1970 à $8,2 \mathrm{~kg}$ en 1997 [1]. La viande blanche contribue actuellement à plus de $40 \%$ de la consommation totale de viande au Maroc [1]; ce secteur génère donc une quantité importante de déchets. Les mesures de traitement sont peu développées et les déchets sont souvent déposés anarchiquement dans les décharges publiques comme celle de la ville de Kénitra, avec des conséquences négatives sur la santé de la population limitrophe $[2,3]$.

La nature de la flore microbienne peut être à l'origine de sérieux problèmes [4]. La destruction des pathogènes des déchets solides de volaille peut se faire par des méthodes physiques (température) ou chimiques (acide acétique, acide probionique, formol) $[5,6]$. Les procédés basés sur la biostabilisation ou la transformation biologique sont aussi économiquement rentables.

Le présent travail vise à étudier la transformation biologique des déchets de volaille en produit stable utilisable comme fertilisant du sol. 


\section{Matériel et méthodes}

\section{2-1. Origine et caractérisation des déchets}

Les déchets de volaille sont collectés d'une unité industrielle (société avicole zone industrielle BIR RAMI Kénitra) située dans la région de Kénitra, par un camion de I'Université des sciences IBN TOFAIL de Kénitra. Ces déchets sont d'origine ॥ Poulets et Dindes 11.

Le pH est déterminé par un pH-mètre type Crison Micro-pH 2000, l'acidité exprimée en pourcentage d'acide lactique par titrage acido-basique, l'azote total par la méthode de Kjeldahl [7], la matière grasse par la méthode du Soxhlet en utilisant l'hexane comme solvant, la matière sèche par séchage 12 heures à $105^{\circ} \mathrm{C}$ de $10 \mathrm{~g}$ d'échantillon, la matière minérale totale par calcination d'une masse exactement pesée dans un four à moufle 24 heures à $550^{\circ} \mathrm{C}$, le phosphore par spectrophotométrie (Afnor V18-106).

La FMAT [Flore Mésophile Aérobie Totale] est énumérée sur PCA [Plate Count Agar] après incubation deux jours à $30^{\circ} \mathrm{C}$. Les Coliformes totaux et fécaux sont dénombrés sur $\mathrm{DCL}$ [Désoxycolate Citrate Lactose Agar] respectivement après incubation à $37{ }^{\circ} \mathrm{C}$ et $44^{\circ} \mathrm{C}$ pendant 24 heures. Les salmonelles sont isolées après enrichissement dans le milieu sélinite de sodium sur milieu Salmonella-Schigella II SS II, après incubation 24 heures à $37^{\circ} \mathrm{C}$. Les clostridiums sont dénombrés sur RCA [Reinforced Clostridium Agar] après incubation 24 heures à $44^{\circ} \mathrm{C}$. Les staphylocoques sont isolés sur milieu sélectif Chapman après incubation 24 heures à $37^{\circ} \mathrm{C}$. Les levures sont dénombrées sur milieu PDA [Potato Dextrose Agar] après incubation trois jours à $30^{\circ} \mathrm{C}$.

\section{2-2. Agents de transformation}

Les bactéries ont été isolées à partir du lait de vache et du jus de presse de canne à sucre sur milieu MRS [Man Rogosa et Sharp] Agar. L'ensemble est ensuite conservé à $4{ }^{\circ} \mathrm{C}$. Elles ont été sélectionnées en se basant sur leur pouvoir acidifiant et antibactérien. La mise en évidence de l'activité bactéricide se fait par la méthode de diffusion en milieu TSA après 24 heures d'incubation à $30^{\circ} \mathrm{C}$.

La suspension obtenue est neutralisée par la soude $(\mathrm{NaOH})$ de façon à obtenir un pH de 6 , puis on ajoute quelques gouttes de catalase pour éliminer l'effet du peroxyde d'oxygène. Des puits remplis par $70 \mu \mathrm{L}$ du surnageant filtré après inondation de boîtes de Petri par les souches pathogènes (Tableav 1), Escherichia coli ATCC25921, Klebsiella pneumoniae, Proteus mirabilis, Staphylococcus aureus ATCC 25923, Streptococcus agalactiae, après incubation 24 heures à $37^{\circ} \mathrm{C}$, les diamètres des zones d'inhibition apparaissant autour des puits sont mesurés. 
Les levures utilisées dans cette fermentation sont isolées à partir de jus de canne à sucre et de lait de vache sur milieu Potato Dextrose Agar (PDA) et les souches sont conservées à $4{ }^{\circ} \mathrm{C}$.

Le pouvoir acidifiant et fermentatif est estimé par mesure du pH final. Les levures sont cultivées sur un milieu semi-synthétique ( $3 \mathrm{~g} / \mathrm{L}$ glucose, $3 \mathrm{~g} / \mathrm{L}$ extrait de levure, $1 \mathrm{~g} / \mathrm{L}$ $\left.\mathrm{MgSO}_{4}, \mathrm{l} \mathrm{g} / \mathrm{L} \mathrm{KH}_{2} \mathrm{PO}_{4,} \mathrm{l} \mathrm{g} / \mathrm{L}\left(\mathrm{NH}_{4}\right)_{2} \mathrm{SO}_{4}\right)$.

Tableau 1 : Microorganismes pathogènes utilisés pour l'étude de l'activité antibactérienne identifiée au laboratoire de recherche et d'analyses médicales de la gendarmerie royale de rabat Maroc.

\begin{tabular}{|c|c|}
\hline Souches pathogènes & Origine \\
\hline Escherichia coli ATCC25921 & Prélèvements urinaires \\
\hline Klebsiella pneumoniae & Prélèvements urinaires \\
Proteus mirabilis & Prélèvements vaginaux \\
Staphylococcus aureus ATCC 25923 & Prélèvements urinaires \\
Streptococcus agalactiae & Prélèvements vaginaux \\
\hline
\end{tabular}

\section{2-3. Identification des souches}

L'identification des souches de levure est réalisée par API 20 E (BioMérieux) / levure, et les bactéries lactiques sont identifiées par API 20E (BioMérieux) / BL. Les souches à identifier ont été cultivées 24 heures à $30^{\circ} \mathrm{C}$. On place $0,1 \mathrm{~mL}$ de cette culture dans des différents puits. Après 24 heures d'incubation, l'identification des souches est effectuée selon la référence du Fabricant.

\section{2-4. Fermentation et stabilisation des déchets}

Cent (100) kilogrammes de déchets sont broyés. Le broyage a été réalisé à l'aide d'un broyeur de type appareil à marteau. Les déchets de volaille sont mis dans des barils en plastique fermés de $350 \mathrm{~kg}$ de capacité chacun additionné de $20 \%$ de mélasse comme source de carbone. Chaque baril est rempli aux deux tiers, le volume restant servant d'espace pour faciliter l'agitation et empêcher un éventuel débordement.

Un baril est inoculé par la bactérie lactique LBLI (20\%), un autre baril inoculé par la souche de levure LSSI $(20 \%)$ et un troisième inoculé par un levain constitué de LBLI (10\%) et LSSI (10\%).

Les levains sont préparés par une culture de la bactérie lactique sur un milieu MRS liquide, et une culture de la levure sur un milieu semi synthétique pendant 24 heures 
d'incubation à $30^{\circ} \mathrm{C}$, après les deux souches sont cultivées dans un milieu à base du lait et la mélasse.

Les barils sont placés dans une chambre à température ambiante et soumis quotidiennement à une agitation manuelle avec un bâton.

Des prélèvements sont effectués tout le long de la fermentation pour des analyses physico-chimiques ( $\mathrm{pH}$, acidité), alors que les analyses microbiologiques sont effectuées avant le traitement et après stabilisation du produit fini.

\section{2-5. Le schéma de la conduite du procédé de fermentation}

Collecte des échantillons<smiles>[C]1C=CC=C1</smiles>

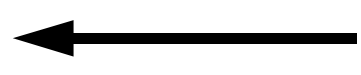

Contrôle analytique

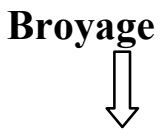

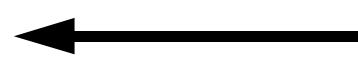

Inoculation

Fermentation<smiles>C=[Tl]</smiles>

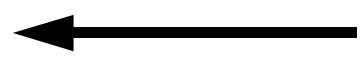

Contrôle analytique

Stabilisation

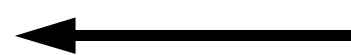

Contrôle analytique

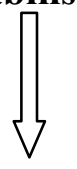

Séchage<smiles>C=[Tl]</smiles>

Conditionnement et entreposage

Contrôle analytique

Figure 1 : Différentes étapes du procédé de traitement biologique des déchets de volaille

Les déchets de volaille collectés ont été broyés et ensuite mélangés avec de la mélasse de canne, en tant que source d'hydrate de carbone, à un ratio de $20 \%$. L'incubation du 
mélange a été réalisée dans des barils en plastique fermés à température ambiante. Une fermentation par inoculation de broyat par un ferment constitué par des souches sélectionnées, en parallèle un contrôle analytique au cours de la fermentation après la baisse nette de la valeur du $\mathrm{pH}$ à partir du deuxième jour pour se stabiliser à 3,9-4,2 après une semaine environ.

Une liquéfaction des déchets a été observée et l'odeur de volaille dans le produit fermenté a été masquée par les produits de fermentation. Après, on procède à un séchage par exposition au soleil, enfin le stockage du produit fini dans des sacs en plastique et sa conservation pour une utilisation ultérieure.

\section{Résultats}

\section{3-1. Caractérisation des déchets de volaille}

La teneur organique $(43,3 \%)$ et les protéines $(15,3 \%)$ se trouvent dans les déchets de volaille à des niveaux élevés (Tableau 1 ). La composition minérale est dominée par le potassium $(56,4 \%)$, suivi du phosphore (10\%) alors que l'azote total n'est que de 2,2 \%.

Tableau 2 : Caractéristiques physico-chimiques des déchets de volaille avant et après traitement par une culture mixte LBLI et LSSI

\begin{tabular}{|c|c|c|}
\hline Paramètres & $\begin{array}{c}\text { Composition des } \\
\text { déchets de volaille } \\
\text { avant traitement } \\
(\%)\end{array}$ & $\begin{array}{c}\text { Composition des } \\
\text { déchets de volaille } \\
\text { après traitement } \\
(\%)\end{array}$ \\
\hline $\mathrm{pH}$ & 6,50 & 3,90 \\
\hline $\begin{array}{c}\text { Matière organique (walkey-Black) } \\
(\%)\end{array}$ & 43,30 & 43,10 \\
\hline Protéines brutes & 15,30 & 14,44 \\
\hline Carbone organique & - & 25,00 \\
\hline Azote total (\%) & 2,20 & 2,31 \\
\hline Phosphore total (\%) & 10,00 & 10,96 \\
\hline Potassium total (\%) & 56,40 & 56,40 \\
\hline Cendres & - & - \\
\hline
\end{tabular}

La FMAT est estimée à $6.10^{8}$ ufc/g (Tableau 2 ). Les bactéries lactiques dominent $\left(8.10^{5} \mathrm{ufc} / \mathrm{g}\right)$ suivies des levures $\left(10^{4} \mathrm{ufc} / \mathrm{g}\right)$, des coliformes et des staphylocoques puis des streptocoques. On a très peu de clostridiums à 180 ufc/g et les salmonelles ne sont 
présentes que dans certains échantillons. La charge microbienne dépasse de loin les normes requises.

\section{3-2. Isolement des souches de fermentation}

Dix souches des bactéries lactiques ont été isolées sur milieu MRS. Elles présentent un fort pouvoir acidifiant allant de $\mathrm{pH} 5,5$ à 4,3, avec une biomasse importante (Tableau 3). Les souches LBLI donne le pH les plus bas.

Tableau 3 : Caractéristiques microbiologiques des déchets de volaille avant et après traitement par le ferment constitué des deux souches (LBLI et LSSI)

\begin{tabular}{|c|c|c|}
\hline Bactéries & $\begin{array}{c}\text { bactéries/g de déchets } \\
\text { de volaille avant } \\
\text { traitement (ufc/g) }\end{array}$ & $\begin{array}{c}\text { bactéries/g de déchets } \\
\text { de volaille après } \\
\text { traitement (ufc/g) }\end{array}$ \\
\hline $\begin{array}{c}\text { FMAT [Flore Mésophile Aérobie } \\
\text { Totale] }\end{array}$ & $7.10^{8}$ & $4.10^{9}$ \\
\hline Bactéries lactiques & $8.10^{5}$ & $2.10^{6}$ \\
\hline Levures & $10^{4}$ & $2.10^{3}$ \\
\hline Coliformes fécaux & $8.10^{2}$ & 0 \\
\hline Staphylocoques & $8.8 .10^{2}$ & 2 \\
\hline Streptocoques & $2.10^{2}$ & 10 \\
\hline Clostridiums & 180 & 0 \\
\hline
\end{tabular}

Tableau 4 : Évolution du pH, de la biomasse et de l'effet bactéricide de dix souches de bactéries lactiques cultivées sur milieu MRS à $30^{\circ} \mathrm{C}$

\begin{tabular}{|c|c|c|c|c|c|c|}
\hline & $\begin{array}{c}\text { Bactérie } \\
\text { lactique }\end{array}$ & Biotope & $\begin{array}{c}\mathbf{p H} \\
\text { initial }\end{array}$ & $\begin{array}{c}\mathbf{p H} \\
\text { final }\end{array}$ & $\begin{array}{c}\text { Biomasse } \\
(\mathbf{D O} \text { à } \mathbf{6 0 0} \\
\mathbf{n m})\end{array}$ & $\begin{array}{c}\text { Effet } \\
\text { bactéricide }\end{array}$ \\
\hline $\begin{array}{c}\text { Lactoccocus } \\
\text { lactis subsp. } \\
\text { cremoris }\end{array}$ & LBL1 & $\mathrm{JP}$ & $\mathbf{6 , 5 0}$ & 4,32 & $\mathbf{0 , 6 8}$ & +++ \\
\hline $\begin{array}{c}\text { Streptococcus } \\
\text { oralis }\end{array}$ & LBL2 & $\mathrm{JP}$ & $\mathbf{6 , 3 0}$ & 5,20 & 0,55 & + \\
\hline $\begin{array}{c}\text { Streptococcus } \\
\text { mitis }\end{array}$ & LBL3 & $\mathrm{JP}$ & $\mathbf{6 , 3 2}$ & 4,43 & 0,77 & ++ \\
\hline $\begin{array}{c}\text { Pediococcus } \\
\text { damnosus }\end{array}$ & LBL4 & $\mathrm{JP}$ & $\mathbf{6 , 5 0}$ & 4,45 & 0,78 & - \\
\hline
\end{tabular}


Afrique SCIENCE 02(1)(2006) 102 - 115

\begin{tabular}{|c|c|c|c|c|c|c|}
\hline & $\begin{array}{l}\text { Bactérie } \\
\text { lactique }\end{array}$ & Biotope & $\begin{array}{c}\text { pH } \\
\text { initial }\end{array}$ & $\begin{array}{c}\text { pH } \\
\text { final }\end{array}$ & $\begin{array}{c}\text { Biomasse } \\
\text { (DO à } 600 \\
\mathrm{~nm})\end{array}$ & $\begin{array}{c}\text { Effet } \\
\text { bactéricide }\end{array}$ \\
\hline $\begin{array}{c}\text { Streeptococcus } \\
\text { Mitis }\end{array}$ & LBL5 & Lait & 6,52 & 4,37 & 0,64 & ++ \\
\hline $\begin{array}{l}\text { Streptococcus } \\
\text { Acidminimus }\end{array}$ & LBL6 & Lait & 6,45 & 4,50 & 0,52 & - \\
\hline $\begin{array}{c}\text { Streptococcus } \\
\text { oralis }\end{array}$ & LBL7 & Lait & 6,20 & 5,02 & 0,40 & - \\
\hline $\begin{array}{l}\text { Streptococcus } \\
\text { thermophilus }\end{array}$ & LBL8 & $J P$ & 6,15 & 4,90 & 0,33 & - \\
\hline Pediococcus sp & LBL9 & $J P$ & 6,20 & 5,20 & 0,25 & - \\
\hline $\begin{array}{c}\text { Leuconostoc } \\
\text { mesenteroides }\end{array}$ & LBLIO & $\mathrm{JP}$ & 6,26 & 5,55 & 0,50 & - \\
\hline
\end{tabular}

Avec,

$\mathrm{JP}$ : jus de presse de la canne à sucre ;

+ : positif; $\quad-:$ négatif

Tableau 5 : Mesure du diamètre de la zone d'inhibition des bactéries lactiques sélectionnées vis à vis des différentes souches pathogènes par la méthode de diffusion sur milieu ISA après 24 heures à $30^{\circ} \mathrm{C}$

\begin{tabular}{|c|c|c|c|c|}
\hline Souches pathogènes & \multicolumn{3}{|c|}{ diamètre d'inhibition (mm) } \\
\hline & LBL1 & LBL2 & LBL3 & LBL5 \\
\hline $\begin{array}{c}\text { Escherichia coli } \\
\text { ATCC25921 }\end{array}$ & $22 \pm 1,26$ & $15 \pm 1,58$ & $18 \pm 1,02$ & $22 \pm 1,20$ \\
\hline $\begin{array}{c}\text { Klebsiella pneumoniae } \\
\text { Proteus mirabilis }\end{array}$ & $20 \pm 1,58$ & $12 \pm 1,41$ & $15 \pm 1,10$ & $18 \pm 1,35$ \\
\hline $\begin{array}{c}\text { Staphylococcus aureus } \\
\text { ATCC25923 }\end{array}$ & $22 \pm 2,23$ & $13 \pm 1,58$ & $16 \pm 1,50$ & $20 \pm 0,32$ \\
\hline $\begin{array}{c}\text { Streptococcus } \\
\text { agalactiae }\end{array}$ & $24 \pm 2,54$ & $15 \pm 1,20$ & $14 \pm 1,12$ & $22 \pm 0,63$ \\
\hline
\end{tabular}


Seules les souches $L B L 1, L B L 2, L B L 3$ et $L B L 5$ ont une activité antibactérienne (Tableau 3 ). Les autres ont présenté une activité quasi-nulle ou absente. La souche LBLI présente la plus forte activité antibactérienne.

Sur les onze souches de levures de biotopes différentes (Tableau 4 ), la souche LSSI, issue du jus de canne à sucre, a montré un fort pouvoir fermentatif. Le pH atteint 4,2 et la biomasse est élevée.

\section{3-3. Identification des souches}

La souche LBLI a été retenue pour la fermentation des déchets de volaille par sa forte activité antibactérienne et son pouvoir acidifiant élevé. La souche LSSI a de même été retenue.

Par la méthode API basée sur l'utilisation de la source de carbone, la bactérie lactique (LBLI) s'avère être Lactoccocus lactis subsp. cremoris et la levure (LSSI) Candida pelliculosa. Les souches ont aussi été mélangées pour constituer un levain mixte de fermentation.

Tableau 6 : Évolution du pH, de la biomasse et de l'effet bactéricide de onze souches de levures cultivées sur milieu MRS à $30^{\circ} \mathrm{C}$

\begin{tabular}{|c|c|c|c|c|c|}
\hline & Levures & Biotope & $\mathrm{pH}$ initial & $\mathrm{pH}$ final & $\begin{array}{c}\text { Biomasse } \\
(\mathrm{DO} \text { a } 600 \mathrm{~nm})\end{array}$ \\
\hline $\begin{array}{c}\text { Candida } \\
\text { Pelliculosa }\end{array}$ & LSS1 & $\mathrm{JP}$ & 6,50 & 4,2 & 0,78 \\
\hline & LSS2 & $\mathrm{JP}$ & 6,40 & 6,60 & 0,20 \\
\hline $\begin{array}{c}\text { Sacharomyce } \\
\text { sp }\end{array}$ & LSS3 & $\mathrm{JP}$ & 6,32 & 6,50 & 0,25 \\
\hline Pichia spl & LSS4 & $\mathrm{JP}$ & 6,45 & 4,80 & 0,68 \\
\hline $\begin{array}{c}\text { Condidat } \\
\text { Sp }\end{array}$ & LSS5 & lait & 6,41 & 6,40 & 0,55 \\
\hline $\begin{array}{c}\text { Candida } \\
\text { Pelliculosa }\end{array}$ & LSS6 & lait & 6,50 & 4,20 & 0,78 \\
\hline $\begin{array}{c}\text { Candida } \\
\text { Pelliculosa }\end{array}$ & LSS7 & lait & 6,50 & 4,20 & 0,78 \\
\hline $\begin{array}{c}\text { Sacharomyce } \\
\text { Cereviseae }\end{array}$ & LSS8 & lait & 6,40 & 7,00 & 0,20 \\
\hline $\begin{array}{c}\text { Candida } \\
\text { culluculosa }\end{array}$ & LSS9 & lait & 6,32 & 6,50 & 0,25 \\
\hline Condida sp & LSS10 & JP & 6,45 & 4,8 & 0,68 \\
\hline Condida sp & LSS11 & JP & 6,41 & 6,4 & 0,55 \\
\hline
\end{tabular}


Avec,

$\mathrm{JP}:$ jus de presse de la canne à sucre

\section{3-4. Fermentation et stabilisation}

Lors de la fermentation de la bactérie lactique LBLI (Figure 2A), le pH diminue progressivement de 5,60 à 4,00 en huit jours. L'acidité se maintient aux alentours de 1,5 du $8^{\mathrm{e}}$ au $14^{\mathrm{e}}$ jour.

Pour la levure LSSI (Tableau 5 et Figure 2B), on note une chute du pH pour atteindre 4,00 après quatre jours de fermentation, avec une acidité de 1,5 .

Le pH des déchets de volaille, préalablement ensemencés par la culture mixte (LSS1+LBL5), diminue durant les trois premiers jours de fermentation (Figure $2 \mathrm{C}$ ) et atteint 3,9. Presque aucune évolution n'est constatée durant la suite de la période de fermentation.

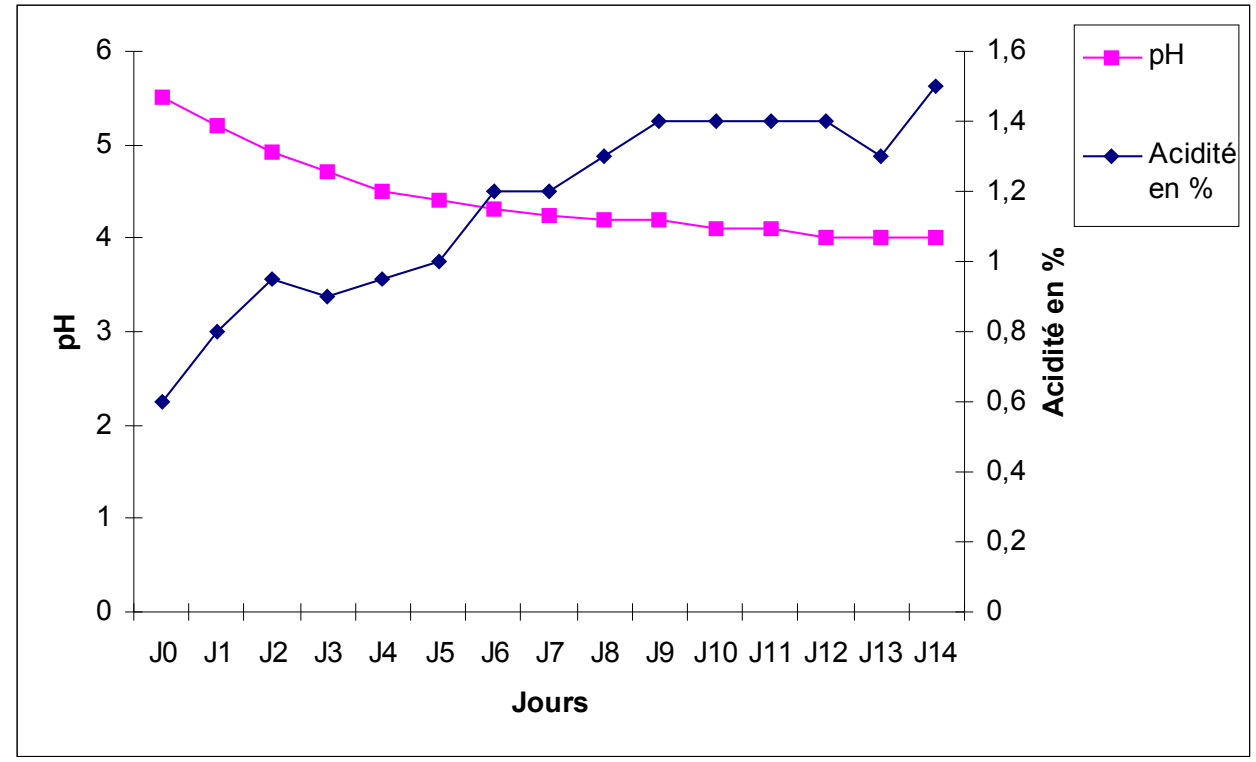

Figure 2A : Evolution du pH et de l'acidité en fonction du temps

(fermentation des déchets par la bactérie lactique LBLI) 


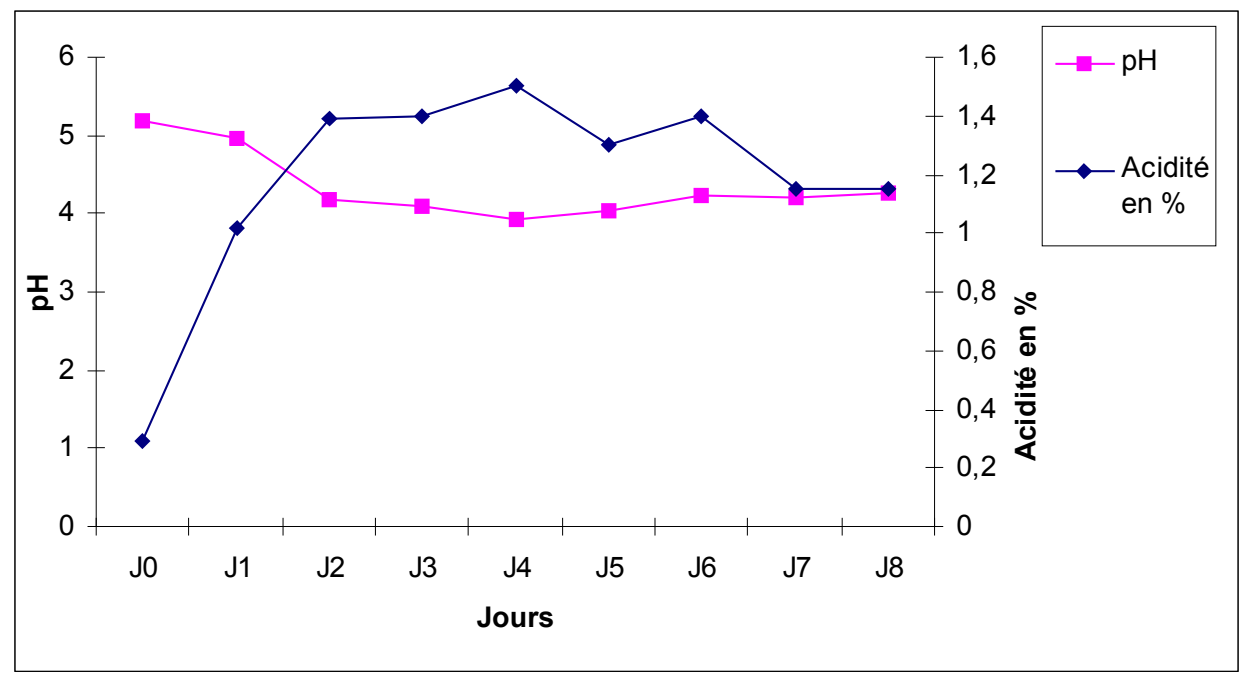

Figure 2B : Evolution du pH et de l'acidité en fonction du temps (fermentation par la levure LSSI)

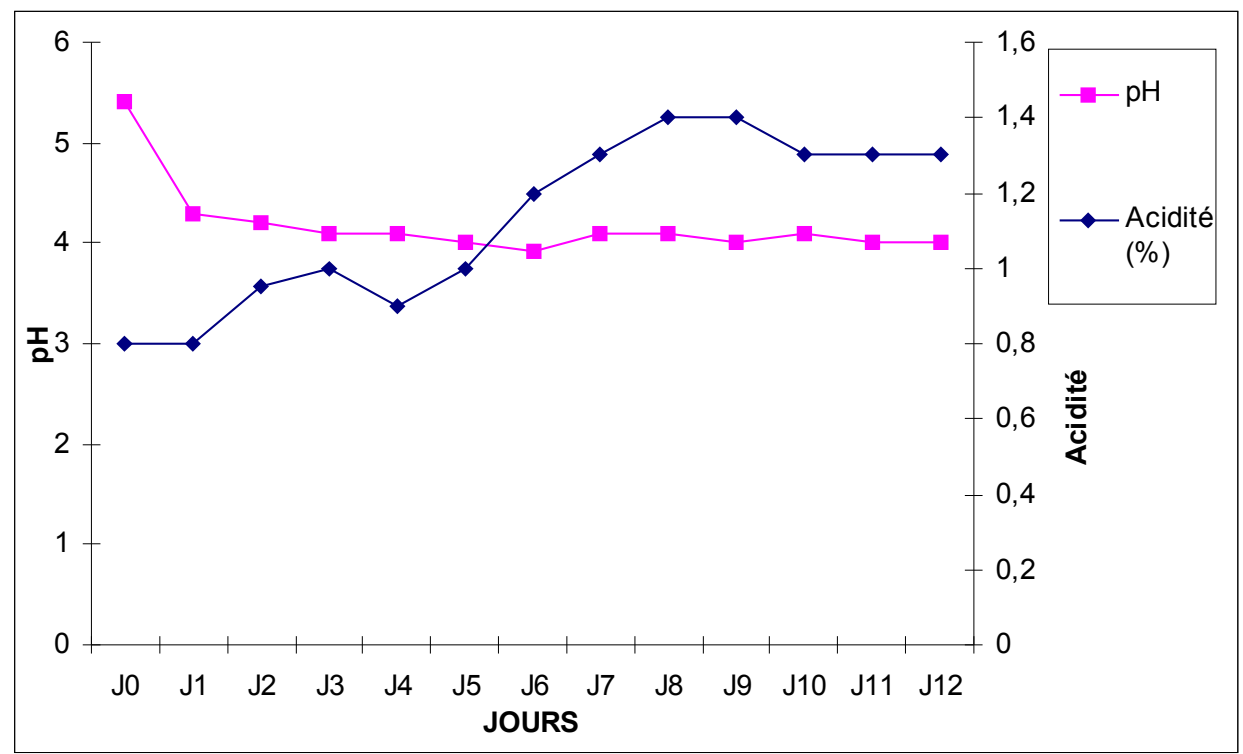

Figure $2 \mathrm{C}$ : Évolution du pH et de l'acidité au cours de la fermentation des déchets de volaille à température ambiante par la culture mixte (LBLI+LSSI) 


\section{3-5. Caractéristiques du produit fini}

La composition physico-chimique est légèrement modifiée (Tableau $\boldsymbol{l}$ ) en plus de la diminution du $\mathrm{pH}(3,9)$. Une légère diminution de la teneur en azote total, matière organique et protéine est constatée. Les taux de phosphore et de potassium sont inchangés.

Pour ce qui est de la composition microbiologique (Tableav 2), la FMAT passe de $7.10^{8}$ à $4.10^{\circ}$. On observe une disparition quasi-totale des groupes de bactéries pathogènes après dix jours de fermentation.

\section{Discussion}

Suite aux analyses physico-chimiques et microbiologiques, il apparaît clairement que les déchets de volaille présentent un impact négatif sur l'environnement et la santé publique par leur matière organique périssable et par leur charge microbiologique pathogène importante.

Deux souches ont été sélectionnées, une bactérie lactique LBLI et une levure LSSI.

Après fermentation des déchets de volaille, nous avons noté une diminution du pH à 3,9. Le taux de phosphore et celui du potassium sont maintenus stables. Par contre, une légère diminution de la teneur en azote total, matière organique et protéine a été constatée. Pour ce qui est des microorganismes, la FMAT a montré une légère augmentation par rapport au témoin, elle passe de $7.10^{8}$ à $4.10^{9}$, alors que les coliformes, staphylococcus, clostridium et salmonelles sont éliminés après dix jours de fermentation.

On observe un effet conjugué de la bactérie lactique LBLl qui possède un pouvoir acidifiant élevé et la levure LSSI qui possède un pouvoir fermentatif très important. La chute $\mathrm{du} \mathrm{pH}$ dans le système de fermentation semi solide est un facteur important pour la stabilisation et la transformation des déchets riches en matière organique $[8,9,10]$. La diminution du pH et l'augmentation de l'acidité traduisent le degré d'hydrolyse des substrats glucidiques (mélasse et substrat glucidique de déchets), sous l'effet des enzymes endogènes (de déchets de volaille) et des enzymes produites par les microorganismes impliqués dans la fermentation.

Les déchets constituent un apport en phosphore (10\%), potassium (56\%), azote total $(2,2 \%)$, matière organique $(43,3 \%)$, et protéines (15,3\%). Ce qui montre une composition équilibrée en phosphore, potassium et azote et qui conduit à un ingrédient intéressant dans la formulation de fertilisation du sol.

La transformation de déchets de volaille par voie biologique, non seulement donne un produit valorisable en fertilisation du sol mais permettrait aussi de réduire l'impact négatif de ces déchets sur l'environnement, la santé et en un mot le développement. 
Des premiers essais de fertilisation ( $10 \mathrm{~m}^{2}$ pour chaque essai) pour les cultures de maïs, pomme de terre, tournesol, ont montré que le produit fermenté est un excellent fertilisant. Des applications à grande échelle sont en cours de réalisation.

\section{Conclusion}

L'intensification de la production des poulets de chair, notamment au Maroc, génère une grande quantité de déchets. L'analyse physico-chimique de ces déchets montre un apport important de phosphore $(10 \%)$, potassium $(56 \%)$, azote total $(2,2 \%)$, matière organique $(43,3 \%)$ et le taux de protéine $(15,3 \%)$.

L'analyse microbiologique montre une charge microbienne pathogène importante, coliformes $\left(8.10^{2} \mathrm{ufc} / \mathrm{g}\right)$, staph $\left(8,8.10^{2}\right.$ ufc $\left./ \mathrm{g}\right)$, streepto $\left(2.10^{2} \mathrm{ufc} / \mathrm{g}\right)$, clostridium (180 ufc/g); ce qui constitue un sérieux problème pour l'environnement et la santé publique.

Dans ce travail, nous avons mis en évidence un procédé biologique pour le traitement de ces déchets. Ainsi, nous avons sélectionné deux souches, une bactérie lactique LBLI et une levure LSSI, possédant un pouvoir fermentatif fort. Après fermentation de ces déchets, nous avons noté la diminution du pH à 3,9 alors que le taux de phosphore et celui du potassium sont maintenus stables. Par contre, une légère diminution de la teneur en azote total, matière organique et protéine, a été constatée. Pour ce qui concerne les microorganismes, la FMAT a subi une légère augmentation, passant de $7.10^{8}$ à $4.10^{9}$, alors que les coliformes, staphylococcus, clostridium, salmonelles sont éliminés au bout de 10 jours de fermentation.

Des essais de fertilisation du sol pour les cultures du maïs, pomme de terre et tournesol, ont montré que le produit fermenté est un excellent fertilisant; des applications à grande échelle étant en cours de réalisation.

\section{Références}

[1] - MADRMP/DE (Ministère de l'Agriculture, du Développement rural et des Pêches maritimes, Direction de l'Élevage, Rabat) - Secteur avicole au Maroc: Situation et perspective. - Rev. Ecol. (Terre Vie), $\mathrm{N}^{\circ} 161$ (1999) 34 http://www.terrevie.ovh.org/al61.htm, http://doc.abhatoo.net.ma/doc/

[2] - A. El Moutawakil - Problèmes de la décharge de Kénitra. - Actes du Séminaire sur le Compostage et la Gestion des Décharges, Kénitra, Maroc, (1995) $103-112$

[3] - M. Benzakour, R. Saissi, G. Didier - Situation actuelle et évolution de la gestion des déchets solides au Maroc/Expérience pilote de la mise en place d'une décharge contrôlée à Essaouira. (2003), 3 p.

http://doc.abhatoo.net.ma/doc/article.php3?id_article $=1239$ 
[4] - S. Essandoubi, M. Faid, M. Elyachioui - Caractérisation microbiologique des déchets d'éviscération de volailles. - Rev. Méd. Afr., (2002) 16

[5] - L. F. Caswel, J. P. Fontenot, K. E. Webb - Utilization of broiler litter ensiled. J. Anim. Sci., 46 (1988) 547-561

[6] - L. W. Smith, G. K. Mc Lead, E. T. Moran - Nutritional and economic value of animal excreta. - J. Animal. Sci., 48 (1979) 145-155

[7] - APHA (American Public Health Association), "S Standard methods for examination of water and waste water $11,19^{\text {th }} \mathrm{Ed}$. (1989) APHA pub. (Washington Dc.)

[8] - M. FAID, H. KARANI, A. ELMARRAKCHI, A. ACHKARI-BEGDOURI, - A biotechnological process for the valorization of fish waste. Bio/Technol: 49 (1994) 237-241

[9] - M. FAID, H. KARANI, A. ELMARRAKCHI, A. ACHKARI-BEGDOURI. - Transformation des déchets de poisson par voie biotechnologique, Cah. Agric., 4 (1995) 109-112

[10] - H. Haaland, LR. Njaa. - Fish silages prepared from raw materiels of varying quality. Chemical analysis related to balance experiments in rats.Fisheridinektorates Skrifter Serie Ernaeing, 3 (1990) 27-35

[11] - M. R. Adams - Safety of industrial lactic acid bacteria. - J. Biotechnol., 68 (2-3) (1999) 171-178

[12] - K. Benabdeljalil - Broiler output stagnates in Morocco, middlemen control the money while producers remain disorganized. - Poultry Intl., 36 (4) (1997) 38-43

[13] - N. Benkerroum, H. Oubel, M. Zahar, S. Dlia, A. Filali-Maltouf - Isolation of a bacteriocin-producing by Lactococcus lactis subsp. lactis and application to control Listeria monocytogenes in jben. - J. Appl. Microbiol., 89 (2000) 960-968

[14] - L. S. Clesceri, A. E. Greenberg, R. R. Trussell - Standard methods for examination of water and wastewater.- $17^{\text {th }}$ ed. (1989), Washington : APHA (American Public Health Association), AWWA (American Water Works Association), WPCF (Water Environment Federation)

[15] - S. Maisnier-Patin, E. Forni, J. Richard - Purification, partial characterisation and mode of action of enterococcin EFS2, an antilisterial bacteriocin produced by a strain of Enterococcus faecalis isolated from a cheese. - Int. J. Food Microbiol., 30 (3) (1995) 255-270

[16] - F. S. Rosane - Cocoa fermentations conducted with a defined microbial cocktail inoculum. - Appl. Environm. Microbiol., 64 (4) (1998) 1477-1483

[17] - M. H. Eljalil, M. Faid, M. Elyachioui. - Procédé biotechnologique pour le traitement et le recyclage des fientes de volaille et essai de valorisation dans l'alimentation de la poule pondeuse. Thèse de Doctorat National, (2000), Faculté des sciences, Université Ibn Tofaiil, Kénitra, Maroc. 